\title{
Shear bond strength between CAD/CAM denture base resin and denture artificial teeth when bonded with resin cement
}

\author{
Sang Yeon Han ${ }^{1}$, Yun-Hee Moon ${ }^{2}$, Jonghyuk Lee ${ }^{3 *}$ \\ 'Department of Prosthodontics, College of Dentistry, Dankook University, Cheonan, Republic of Korea \\ ${ }^{2}$ Department of Dental Laboratory Technology, Daejeon Health Institute of Technology, Daejeon, Republic of Korea \\ ${ }^{3}$ Department of Prosthododntics, College of Dentistry, Dankook Univeristy, Cheonan, Republic of Korea
}

\begin{abstract}
PURPOSE. The bond strengths between resin denture teeth with various compositions and denture base resins including conventional and CAD/CAM purposed materials were evaluated to find influence of each material. MATERIALS AND METHODS. Cylindrical rods (6.0 mm diameter $\times 8.0 \mathrm{~mm}$ length) prepared from pre-polymerized CAD/CAM denture base resin blocks (PMMA Block-pink; Huge Dental Material, Vipi Block-Pink; Vipi Industria) were bonded to the basal surface of resin teeth from three different companies (VITA MFT ${ }^{\circledR}$; VITA Zahnfabrik, Endura Posterio $^{\circledR}$; SHOFU Dental, Duracross Physio ${ }^{\circledR}$; Nissin Dental Products Inc.) using resin cement (Super-Bond C\&B; SUN MEDICAL). As a control group, rods from a conventional heat-polymerizing denture base resin (Vertex ${ }^{\mathrm{TM}}$ Rapid Simplified; Vertex-Dental B.V. Co.) were attached to the resin teeth using the conventional flasking and curing method. Furthermore, the effect of air abrasion was studied with the highly cross-linked resin teeth (VITA MFT ${ }^{\circledR}$ ) groups. The shear bond strengths were measured, and then the fractured surfaces were examined to analyze the mode of failure. RESULTS. The shear bond strengths of the conventional heat-polymerizing PMMA denture resin group and the CAD/CAM denture base resin groups were similar. Air abrasion to VITA MFT ${ }^{\circledR}$ did not improve shear bond strengths. Interfacial failure was the dominant cause of failure for all specimens. CONCLUSION. Shear bond strengths of CAD/CAM denture base materials and resin denture teeth using resin cement are comparable to those of conventional methods. [J Adv Prosthodont 2020;12:251-8]
\end{abstract}

KEYWORDS: CAD/CAM denture base resin; Denture resin tooth; Resin cement; Shear bond strength; Mode of failure

\section{INTRODUCTION}

Complete denture is one of the most frequently used treatment options for completely edentulous patients. Although dental implants have provided an alternative treatment approach to complete dentures, the complexity of the treatment, surgical demand, and the financial burden make complete dentures an inevitable treatment option for many

\section{Corresponding author:}

Jonghyuk Lee

Department of Prosthodontics, School of Dentistry, Dankook University,

119 Dandae-Ro, Dongnam-gu, Cheonan, 31116, Republic of Korea

Tel. +82415501975: e-mail, hyuk928@dankook.ac.kr

Received November 5, 2018 / Last Revision September 7, 2020 / Accepted October 5, 2020

(C) 2020 The Korean Academy of Prosthodontics

This is an Open Access article distributed under the terms of the Creative Commons Attribution Non-Commercial License (http://creativecommons. org/licenses/by-nc/4.0) which permits unrestricted non-commercial use, distribution, and reproduction in any medium, provided the original work is properly cited. patients. $^{1}$

Poly methyl methacrylate (PMMA) resin has been used for dentures since the late 1930s. ${ }^{2}$ For decades, the physical properties of PMMA resin have been improved and the traditional denture fabrication methods have been accepted as clinically predictable. ${ }^{2-4}$ However, complete dentures fabricated with conventional methods have several disadvantages such as presence of unreacted monomers, ${ }^{5}$ risk of candidiasis caused by harbored candida albicans, ${ }^{6}$ minimum of 4 to 5 patient visits, ${ }^{4,7}$ and difficulty in producing an optimal duplicate denture. ${ }^{8}$ Pre-polymerized acrylic resin can help address several of these potential disadvantages by using Computer-aided design/computer-aided manufacturing (CAD/CAM) systems during manufacturing. . $^{79-12}$

The CAD/CAM system enables automated fabrication of a $3 \mathrm{D}$ object, and has been used in dentistry since the 1980s-mainly for fixed prosthodontic restorations. ${ }^{9}$ The transition to the fabrication of removable prosthodontic restorations was attempted in the $1990 \mathrm{~s} .{ }^{9}$ Maeda et al. ${ }^{13}$ 
introduced a method for fabricating complete dentures using a rapid prototyping (printing) technology, and Kawahata et al. ${ }^{14}$ introduced a milling technique to duplicate existing dentures. Currently, two manufacturing methods are available for CAD/CAM dentures: the subtractive milling method and the additive printing method. ${ }^{10,15}$ The milling method can produce dentures as: i) a single body with the denture base and resin teeth in one piece, ${ }^{12,16}$ or ii) with the denture base and artificial teeth as separate pieces, an approach which then requires an additional bonding process., ${ }^{916-20} \mathrm{At}$ present, the method producing a denture base with sockets for ready-made denture teeth by milling from a pre-polymerized resin block is more popular. ${ }^{716-20}$ The benefits of this method have been reported as having better fit and retention due to the lack of polymerization shrinkage, ${ }^{10,11,17,18,21}$ and allowing various commercially available denture teeth $^{10,17}$ with better physical properties ${ }^{15,22-24}$ and aesthetic multi-layered appearance. ${ }^{3,25-30}$

Preformed acrylic resin teeth have been used since 1940 and continuously modified to improve physical properties (e.g., wear resistance, color stability)..$^{3,23-33}$ However, compared to conventional acrylic denture teeth, the stronger resin denture teeth with composite or cross-linking agents demonstrated lower bond strength. ${ }^{26,31}$ Many studies have aimed to improve the bond strength between resin denture teeth and denture bases..$^{22,25,34-40}$ For conventional dentures, debonding of artificial teeth is a major problem causing almost one third of all denture repairs. ${ }^{41,42}$ When resin denture teeth were bonded to a milled denture base, they were usually fixed with a methacrylate-based bonding material. ${ }^{16,17}$ Suzuki et al. ${ }^{25}$ reported that the application of an adhesive agent containing 4-methacryloxyethyl trimellitate anhydride (4-META) on highly cross-linked denture teeth before heat polymerization of an acrylic denture base resin improved the bond strength. However, studies on the bond strength between these teeth and CAD/CAM fabricated denture bases are scarce.

This study aims to evaluate the bond strengths of three types of denture teeth (two composite denture teeth and one highly cross-linked denture teeth) to two different CAD/CAM purposed pre-polymerized denture base materials. The null hypothesis was that the resin denture tooth type, denture base resin type, and air abrasion on the ridge lap surface of a denture tooth will have no effect on the shear bond strength between the denture artificial tooth and denture resin bonded with resin cement.

\section{MATERIALS AND METHODS}

A summary of materials used are presented in Table 1. Specimens consist of a denture-base resin rod bonded to the ridge-lap surface of a resin denture tooth. A schematic of the completed specimen is presented in Figure 1. Three types of resin maxillary molar denture teeth were selected: two composite resin denture teeth with different filler contents (Endura Posterio ${ }^{\circledR}$ with $47 \%$ organic filler and Duracross Physio $^{\circledR}$ with $68 \%$ organic filler), ${ }^{23}$ and a recently introduced highly cross-linked resin denture teeth (VITA MFT $\left.{ }^{\circledR}\right){ }^{29}$ Each denture tooth was embedded in a mold with autopolymerizing acrylic resin (Ortho-Jet) to form a resin block of $30 \mathrm{~mm} \times 20 \mathrm{~mm}$ (diameter $\times$ height). The ridge-lap sur-

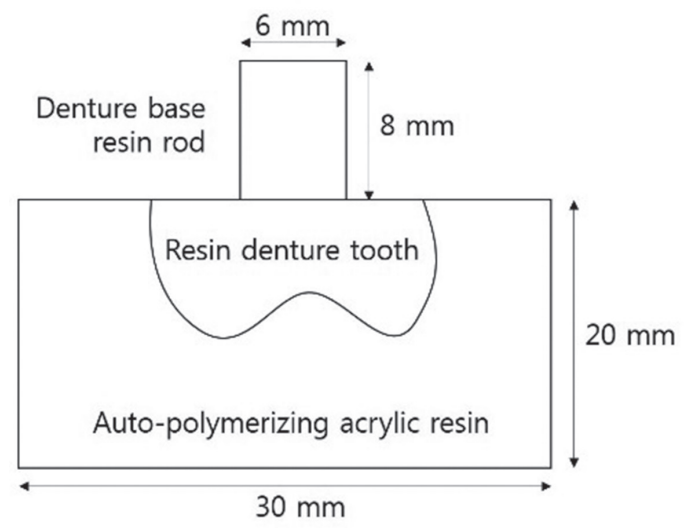

Fig. 1. Schematic diagram of the specimen.

Table 1. Materials used for the experiment

\begin{tabular}{llll}
\hline \multicolumn{1}{c}{ Materials } & \multicolumn{1}{c}{ Identification } & \multicolumn{1}{c}{ Manufacturer } & Composition \\
\hline \multirow{2}{*}{ Resin denture tooth } & VITA MFT $^{\circledR}$ & VITA Zahnfabrik, Bad Säckingen, Germany & Highly cross-linked acrylic resin \\
& $\begin{array}{l}\text { Duracross Physio }{ }^{\circledR} \\
\text { Endura Posterio }{ }^{\circledR}\end{array}$ & Nissin Dental Products, Kyoto, Japan & Composite resin \\
Auto-polymerizing acrylic resin & Shofu Dental, Kyoto, Japan & Composite resin \\
& Ortho-Jet & Lang Dental Mfg Co., Wheeling, IL, USA & PMMA \\
Denture base resin & Vertex TM Rapid Simplified & Vertex-Dental B.V. Co., Soesterberg, Netherland PMMA & PMMA \\
& PMMA Block - pink & Huge Dental Material, Shanghai, China & PMMA \\
Resin cement & Vipi Block - Pink & Vipi Industria, São Paulo, Brazil & MMA, 4-META \\
\hline
\end{tabular}


faces of the embedded resin denture teeth were flattened and polished using 400-, 600-, 800-, 1000-, and 1200-grit $\mathrm{SiC}$ abrasive paper (R\&B, Daejeon, Korea) serially in a water-cooled automatic polishing device (LaboPol-5, Struers, Copenhagen, Denmark) at $400 \mathrm{rpm}$. All base specimens were cleaned ultrasonically with distilled water for 10 minutes and dried with water and oil-free air for 20 seconds. The resin blocks with VITA MFT ${ }^{\circledR}$ teeth were divided into non-treated and air-abraded subgroups. Air abrasion was achieved with $50 \mu \mathrm{m}$ aluminum oxide (Cobra, Renfert Gmbh, Hilzinge, Germany) for 10 seconds at $0.2 \mathrm{MPa}$ from a distance of $10 \mathrm{~mm}$ to the surface. Resin blocks prepared in this manner were ready to receive denture-base resin rods. Group and specimen conditions are summarized in Table 2. Control groups received conventional heat-polymerizing denture base resin rods, while the experimental groups received pre-polymerized denture resin rods.

Rod preparation and attachment procedures were completed as follows. First, pre-polymerized denture resin rods (6.0 $\mathrm{mm}$ diameter $\times 8.0 \mathrm{~mm}$ length) were prepared from two types of pre-polymerized PMMA denture resin CAD/ CAM disks (PMMA Block-pink and Vipi Block-Pink) using a milling machine (D43, Yenadent, Istanbul, Turkey). Rods were bonded to the ridge lap surface of the denture resin teeth using a methacrylate-based resin cement (Super-Bond $\mathrm{C} \& \mathrm{~B}$ pink) containing 4-META according to the manufacturer's (Sun medical) instructions. Before applying the resin cement, the ridge lap surface was conditioned with Super Bond monomer for 30 seconds. To minimize the excess resin cement, transparent tape $(54 \mu \mathrm{m}$ thickness with a $6 \mathrm{~mm}$ diameter hole) was used. After bonding, the residual excess cement was trimmed using a dental explorer.

Extra rods from CAD/CAM blocks were used to create molds for heat-polymerizing resin denture base rods by imprinting them into a silicone impression material (SilagumPutty, DMG, Hamburg, Germany). Wax rods $(6.0 \mathrm{~mm}$ diameter $\times 8.0 \mathrm{~mm}$ length) formed from the silicone molds were attached to the ridge-lap surface of the resin denture teeth, and they were invested in denture flasks with dental plaster (Neo Gemma 70, Samwoo Co., Ulsan, Korea). After the plaster hardened, wax was removed with hot water. Heat-polymerizing PMMA denture resin $\left(V_{e r t e x}{ }^{\mathrm{TM}}\right.$ Rapid Simplified) was mixed and packed according to the manufacturer's instructions to fill the plaster mold, and polymerization was completed in an automatic polymerization water tank (Type 5518, KaVo EWL, Biberach, Germany). After polymerization, specimens were carefully deflasked, and excess resin was trimmed using a laboratory knife.

All the prepared specimens were stored in distilled water at $37^{\circ} \mathrm{C}$ for 24 hours according to the ISO/TS 11405 before measuring shear bond strength. The shear bond strength was examined using a Universal Testing Machine (OTU05D, Oriental TM Corp., Gyeonggi-do, Korea) with a special jig at a crosshead speed of $0.5 \mathrm{~mm} / \mathrm{min}$ until bonding failure occurred. Figure 2 presents the experimental setup for measuring the shear bond strengths. Shear bond strengths were calculated using the following formula:

Shear bond strength $=$ Force to failure/bonding area; $\mathrm{MPa}=\mathrm{N} / \mathrm{mm}^{2}$

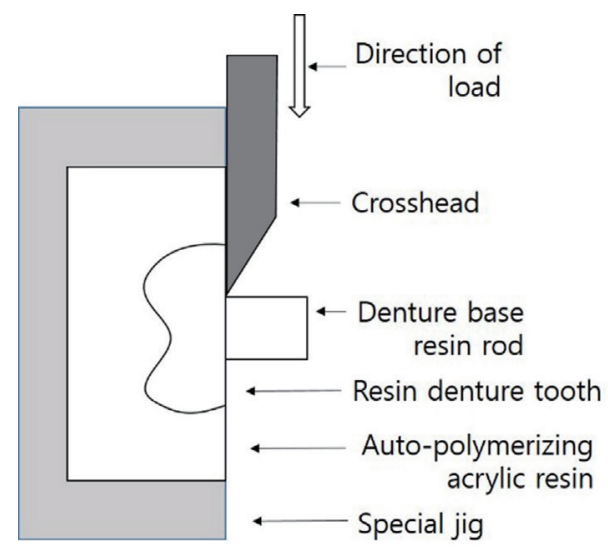

Fig. 2. Schematic drawing of shear bond strength test. The load was applied directly to the interface.

Table 2. Groups of the specimen

\begin{tabular}{|c|c|c|c|c|}
\hline Group name & Detail & of ec & h group & Number of specimens \\
\hline VC & VITA MFT $^{\circledR}$ & + & Heat-polymerizing PMMA (Flasked) & $n=10$ \\
\hline $\mathrm{DC}$ & Duracross Physio ${ }^{\circledR}$ & + & Heat-polymerizing PMMA (Flasked) & $n=10$ \\
\hline EC & Endura Posterio ${ }^{\circledR}$ & + & Heat-polymerizing PMMA (Flasked) & $n=10$ \\
\hline VP & VITA MFT ${ }^{\circledR}$ & + & PMMA Block - pink (Resin cement) & $\mathrm{n}=10$ \\
\hline VPA & VITA MFT ${ }^{\circledR}$ (Air abraded) & + & PMMA Block - pink (Resin cement) & $n=10$ \\
\hline $\mathrm{DP}$ & Duracross Physio ${ }^{\circledR}$ & + & PMMA Block - pink (Resin cement) & $n=10$ \\
\hline EP & Endura Posterio ${ }^{\circledR}$ & + & PMMA Block - pink (Resin cement) & $\mathrm{n}=10$ \\
\hline W & VITA MFT ${ }^{\circledR}$ & + & Vipi Block - Pink (Resin cement) & $\mathrm{n}=10$ \\
\hline WA & VITA MFT ${ }^{\circledR}$ (Air abraded) & + & Vipi Block - Pink (Resin cement) & $\mathrm{n}=10$ \\
\hline DV & Duracross Physio ${ }^{\circledR}$ & + & Vipi Block - Pink (Resin cement) & $n=10$ \\
\hline EV & Endura Posterio ${ }^{\circledR}$ & + & Vipi Block - Pink (Resin cement) & $n=10$ \\
\hline
\end{tabular}


The failure mode was defined and categorized as follows: i) cohesive failure of denture tooth (fracture within the body of resin denture tooth), ii) cohesive failure of denture base (fracture within the body of denture base resin), iii) adhesive failure (failure between a denture tooth and a denture base), iv) interfacial failure on the bonding surface of denture tooth (little or no resin cement left on a denture tooth surface), v) interfacial failure on the bonding surface of denture base (little or no resin cement left on a denture resin surface), and vi) mixed failure (cohesive and interfacial failure at the same time on any side). The fractured surfaces were scanned with a digital scanner (EPSON Perfection V500 Photo scanner, Seiko Epson Corporation, Nagano, Japan) at an input resolution of $12800 \mathrm{dpi}$ and assessed on a personal computer using an imaging software, Adobe Photoshop CS5 (Adobe System, Inc., San Jose, CA, USA), at a zoom of $200 \%$ to define fracture patterns. Scanning electron microscopy (SEM, ZEISS GeminiSEM 500, Carl Zeiss Corp., Oberkochen, Germany) observation was performed at magnifications of $\times 50, \times 500$, and $\times 1000$ to examine the micro-structure of the fractured surfaces.

The topographical effect of air abrasion on VITA MFT $^{\circledR}$ was evaluated with SEM and surface roughness measurement using a non-contact 3D microsurface profiler (NV-2000, Nano System Co., Daejeon, Korea) before and after treatment. Each specimen was measured 6 times, and 4 specimens were used for each measurement.

The mean shear bond strengths of groups were calculated and analyzed using the IBM SPSS Statistics v24.0 (IBM Corp., Chicago, IL, USA) program. The significance of the differences in shear bond strength among the groups was analyzed using one-way ANOVA, and a post-hoc comparison was performed using the Tukey HSD test. The mean surface roughness of the VITA MFT ${ }^{\circledR}$ tooth before and after air abrasion was analyzed using the Kruskal-Wallis test, and a post-hoc comparison was performed using the MannWhitney $U$ test. The level of significance was set at 5\%.

\section{RESULTS}

Table 3 and Figure 3 present means and standard deviations of the shear bond strengths of all groups. There were no significant differences among the groups except for when compared to the Endura Posterio ${ }^{\circledR}$ tooth groups. The Endura Posterio ${ }^{\circledR}$ tooth groups showed lower shear bond strengths than other denture teeth groups; Group EC demonstrated significantly lower shear bond strength other than Group DV $(P<.05)$. Among the Duracross Physio ${ }^{\circledR}$ tooth groups, Group DV demonstrated a significantly lower bond strength when compared to group DP $(P<.05)$. The VITA MFT $^{\mathbb{B}}$ tooth group demonstrated shear bond strength comparable to those of the other groups. Air abrasion treatment had no influence on the shear bond strength of VITA MFT $^{\circledR}$ teeth. Table 4 lists the results of the Tukey HSD test among the groups.

SEM images of the VITA MFT ${ }^{\mathbb{B}}$ teeth revealed differences in topography after air abrasion. Before the air abra- sion, the ridge lap surfaces of the teeth demonstrated irregular track-like wear surfaces caused by the polishing procedure. However, after the air abrasion, the surfaces became smoother with several crater-like irregularities produced by abrasion particles (Fig. 4). Table 5 presents the means and standard deviations of Ra values (in $\mu \mathrm{m}$ ) of the VITA MFT $^{\mathbb{B}}$ tooth surfaces before and after air abrasion. After air abrasion, surface roughness decreased, but this difference was not statistically significant $(P<.05)$.

The result of failure mode analysis is presented in Figure 5. In the control groups, adhesive failure was the most common cause of failure; partial cohesive failure was the cause in the remaining specimens and occurred on the tooth surface. Group EC demonstrated more cohesive failures $(50 \%)$ compared to the other groups $(20 \%$ each). This

Table 3. Mean shear bond strength and standard deviation of all groups tested (Unit: MPa)

\begin{tabular}{ccccc}
\hline & $V$ & $V A$ & $D$ & $E$ \\
\hline$C$ & $18.84 \pm 4.38$ & - & $19.31 \pm 5.16$ & $10.17 \pm 4.34$ \\
$P$ & $19.61 \pm 3.07$ & $19.57 \pm 3.97$ & $21.80 \pm 3.00$ & $16.90 \pm 3.48$ \\
$V^{\$}$ & $19.79 \pm 2.41$ & $19.85 \pm 3.13$ & $14.35 \pm 4.56$ & $17.20 \pm 3.46$ \\
\hline
\end{tabular}

V: VITA MFT ${ }^{\circledR}$, VA: air abraded VITA MFT ${ }^{\circledR}$, D: Duracross Physio ${ }^{\oplus}$, E: Endura Posterio ${ }^{\circledR}$, C: conventional heat-polymerizing resin, P: PMMA Block - pink prepolymerized resin block, $V^{\$}$ : Vipi Block - Pink pre-polymerized resin block.

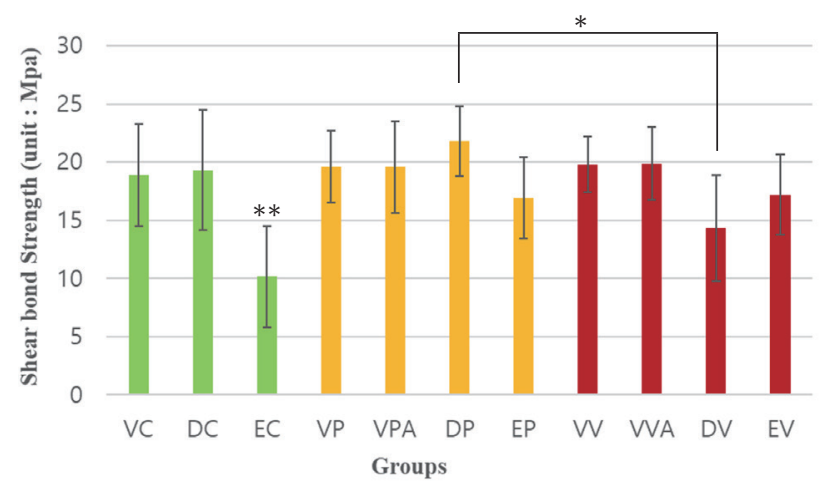

Fig. 3. Mean shear bond strength of all the groups tested. VC: VITA $\mathrm{MFT}^{\circledR}+$ heat-polymerizing resin, DC: Duracross Physio $^{\circledR}+$ heat-polymerizing resin, EC: Endura Posterio ${ }^{\circledR}$ + heat-polymerizing resin, VP: VITA $M{ }^{\circledR}+$ PMMA Block - pink, VPA: air abraded VITA MFT ${ }^{\circledR}+$ PMMA Block - pink, DP: Duracross Physio $^{\circledR}+$ PMMA Block - pink, EP: Endura Posterio $^{\circledR}+$ PMMA Block - pink, VV: VITA MFT $^{\circledR}+$ Vipi Block - Pink, VVA: air abraded VITA MFT ${ }^{\circledR}+$ Vipi Block Pink, DV : Duracross Physio ${ }^{\circledR}+$ Vipi Block - Pink, EV: Endura Posterio ${ }^{\circledR}+$ Vipi Block - Pink.

* denotes a significant difference between the groups $(P<$ $.05)$.

** denotes a significant difference to all other groups $(P<$ $.05)$. 
Table 4. Tukey HSD test on the shear bond strength of each group

\begin{tabular}{|c|c|c|c|c|c|c|c|c|c|c|c|}
\hline & DC & EC & VC & DP & EP & VP & VPA & DV & EV & W & WA \\
\hline DC & & $\leq .000$ & 1.000 & .949 & .959 & 1.000 & 1.000 & .187 & .984 & 1.000 & 1.000 \\
\hline EC & * & & $\leq .000$ & $\leq .000$ & .013 & $\leq .000$ & $\leq .000$ & .423 & .007 & $\leq .000$ & $\leq .000$ \\
\hline VC & & * & & .857 & .991 & 1.000 & 1.000 & .315 & .998 & 1.000 & 1.000 \\
\hline DP & & * & & & .203 & .979 & .976 & .003 & .284 & .989 & .991 \\
\hline EP & & * & & & & .914 & .920 & .939 & 1.000 & .874 & .861 \\
\hline VP & & * & & & & & 1.000 & .128 & .959 & 1.000 & 1.000 \\
\hline VPA & & * & & & & & & .134 & .963 & 1.000 & 1.000 \\
\hline DV & & & & * & & & & & .882 & .100 & .092 \\
\hline EV & & * & & & & & & & & .934 & .925 \\
\hline W & & * & & & & & & & & & 1.000 \\
\hline WA & & * & & & & & & & & & \\
\hline
\end{tabular}

DC: Duracross Physio ${ }^{\circledR}$ + heat-polymerizing resin, EC: Endura Posterio ${ }^{\circledR}+$ heat-polymerizing resin, VC: VITA MFT ${ }^{\circledR}+$ heat-polymerizing resin, DP: Duracross Physio ${ }^{\circledR}+$ PMMA Block - pink, EP: Endura Posterio ${ }^{\circledR}+$ PMMA Block - pink, VP: VITA MFT ${ }^{\circledR}+$ PMMA Block - pink, VPA: air abraded VITA MFT ${ }^{\circledR}+$ PMMA Block - pink, DV: Duracross Physio ${ }^{\circledR}+$ Vipi Block - Pink, EV: Endura Posterio ${ }^{\circledR}+$ Vipi Block - Pink, W: VITA MFT ${ }^{\circledR}+$ Vipi Block - Pink, WA: air abraded VITA MFT ${ }^{\circledR}+$ Vipi Block - Pink. * denotes a significant difference between the groups $(P<.05)$.
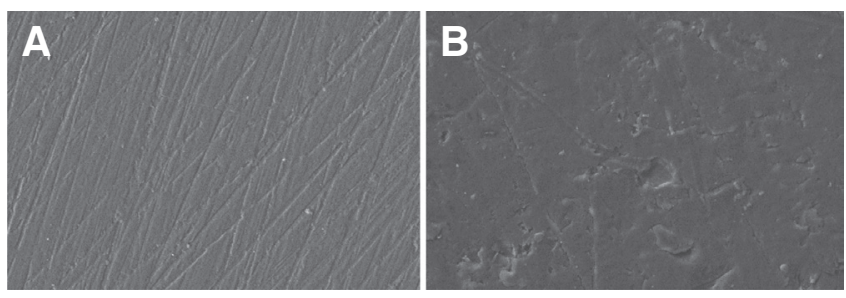

Fig. 4. SEM images of ridge lap surface of VITA $M^{\circledR}{ }^{\circledR}(A)$ before air abrasion, (B) after air abrasion (original magnification $\times 1000$ ).

Table 5. Mean and standard deviation of the surface roughness of VITA MFT $^{\circledR}$ before and after air abrasion (unit: $\mu \mathrm{m}$ )

\begin{tabular}{ccc}
\hline & Before air abrasion & After air abrasion \\
\hline Mean \pm SD & $0.26 \pm 0.04$ & $0.20 \pm 0.03$ \\
\hline
\end{tabular}

SD: standard deviation

tendency was also observed in the experimental groups with Endura Posterio ${ }^{\circledR}$ tooth (Group EP and EV), as only 2 cases of interfacial failure on the tooth surface were observed in each group. The remaining groups demonstrated a higher incidence of interfacial failure on the tooth surface (more than half of all specimens). SEM images of examples of interfacial failure at a magnification of $50 \times$ are presented in Figure 6.

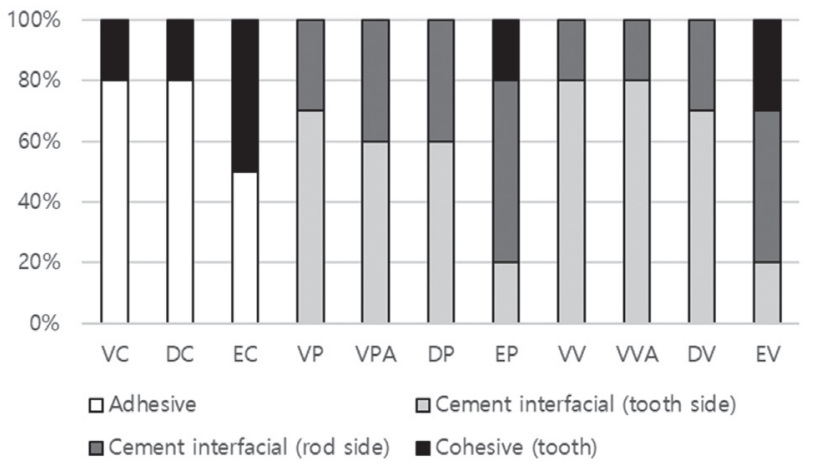

Fig. 5. Failure mode analysis of groups.

VC: VITA $\mathrm{MFT}^{\circledR}+$ heat-polymerizing resin, DC: Duracross Physio $^{\circledR}+$ heat-polymerizing resin, EC: Endura Posterio ${ }^{\circledR}$ + heat-polymerizing resin, VP: VITA MTF ${ }^{\circledR}+$ PMMA Block - pink, VPA: air abraded VITA MFT ${ }^{\circledR}+$ PMMA Block - pink, DP: Duracross Physio ${ }^{\circledR}+$ PMMA Block - pink, EP: Endura Posterio $^{\circledR}+$ PMMA Block - pink, VV: VITA MFT ${ }^{\circledR}+$ Vipi Block - Pink, VVA: air abraded VITA MFT ${ }^{\circledR}+$ Vipi Block Pink, DV: Duracross Physio ${ }^{\circledR}+$ Vipi Block - Pink, EV: Endura Posterio ${ }^{\circledR}+$ Vipi Block - Pink.
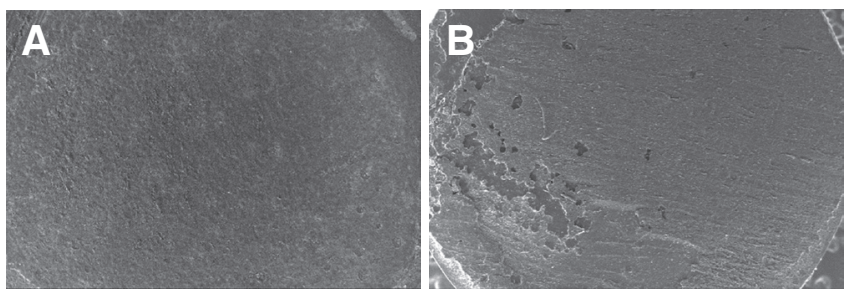

Fig. 6. SEM image of the fractured surface with interfacial failure. (A) side of denture tooth (Duracross Physio ${ }^{\circledR}$ ), (B) side of denture resin (PMMA Block - pink)(original magnification $\times 50$ ). 


\section{DISCUSSION}

The aim of the study was to evaluate bond strengths of CAD/CAM denture base resins and resin denture teeth. The denture bases and teeth were bonded with a methacrylate-based resin cement and then compared with the conventional method of using heat-polymerizing denture base resin. The bond strengths of the experimental groups were similar to those of the control groups. However, within the limitations of this study, the null hypothesis that the type of resin denture tooth and denture base resin does not affect the bond strength was weakly rejected since there were some statistically significant differences among the groups. On the other hand, this study revealed that bond strengths between resin denture teeth and pre-polymerized CAD/ CAM denture base resins using a methacrylate-based resin cement are comparable to the bond strength between resin denture teeth and heat-polymerized denture resin.

An advantage of CAD/CAM dentures fabricated as a single piece is strong bonding between resin teeth and denture base. ${ }^{12}$ However, this type of denture is associated with an incidence of rapid tooth wear as high as $20 \%$. $^{12,15}$ Wear resistance of denture teeth is important to maintain proper vertical dimension and functional occlusion. ${ }^{23}$ On the contrary, methods used to manufacture denture bases and teeth as separated pieces allow the use of preformed artificial denture teeth with improved physical properties. ${ }^{7,16,20}$ Several materials have been used to fulfill esthetic demands and physical properties as denture teeth. Porcelain teeth have higher wear resistance and esthetic features but have poor retention to denture base resin. ${ }^{3}$ Acrylic resin teeth, on the contrary, provide better bonding to denture resin but have poor wear resistance. ${ }^{3}$ Composite resins with various fillers and crosslinking agents were added to conventional acryl resin denture teeth to improve physical properties. ${ }^{23,27,32,35}$ Zeng et al. ${ }^{23}$ and Loyaga-Rendon et al. ${ }^{27}$ reported that filler contents and geometry affects the hardness of the resin tooth; in this regard, they confirmed that Duracross Physio ${ }^{\circledR}$ has higher filler contents and hardness than Endura Posterio ${ }^{\circledR}$. Choi et al..$^{24}$ and Lee et al..$^{28}$ compared Duracross Physio ${ }^{\circledR}$, Endura Posterio ${ }^{\circledR}$ and plane acrylic rein teeth to show better wear resistance and color stability of Duracross Physio ${ }^{\circledR}$. Suzuki et $a l^{25}$ mentioned that the increased degree of crosslinking enhances the hardness and abrasion resistance, but also prevents the penetration of methyl methacrylate (MMA) monomer from the denture base resin into the resin tooth matrix. Many studies have confirmed that these reinforced resin teeth do not bond as well as conventional acrylic resin denture teeth. ${ }^{25,26,31,36}$ To overcome this problem, various methods have been attempted. Most of these high strength resin teeth allocate a softer resin layer at the ridgelap side. ${ }^{25,27}$ Bonding between conventional denture resin and resin teeth is primarily achieved by mechanical retention through intimate contact and chemical bonding through diffusion of the monomers into the tooth resin. ${ }^{27,32,34-36}$ The diffusion rate is higher in conventional acryl resin compared with cross-linked acrylic resin or composite resin,,$^{25,27,32}$ and can be enhanced with high temperature and pressure..$^{32-35}$ This reflects higher bond strength of heat-polymerizing denture resins to resin denture teeth. ${ }^{35,36}$ Therefore, this study compared the bond strength of experimental groups to heat-polymerized denture resin and denture tooth.

$\mathrm{CAD} / \mathrm{CAM}$ dentures fabricated from pre-polymerized resin blocks have several advantages over conventional ones: better fitness, ${ }^{17,18}$ higher retention, ${ }^{11,21}$ and lower monomer release. ${ }^{16}$ Although, the use of pre-polymerized material reduces distortion from polymerization during denture fabrication, this also eliminates the possibility of chemical reactions that are essential to form a strong bond between denture resin and resin tooth. Suzuki et al. ${ }^{25}$ examined the effect of grinding and 4-META application and concluded that the use of 4-META more effectively increased bond strengths. Saavedra et al. ${ }^{38}$ also studied the effect of an MMA-based bonding agent and sandblasting and demonstrated that an MMA-based bonding agent improved the bond strength regardless of the type of denture base resin. However, all these studies were conducted with denture resins polymerizing in contact with denture teeth so as to have enough time to react. Our study demonstrated that the MMA based resin cement, which contains 4-META, could provide enough bond strength even with pre-polymerized denture base resins to be comparable to the conventional heat-polymerized resin.

VITA MFT $^{\circledR}$ is a recently introduced high cross-linked denture tooth product that can be used with the VITA VIONIC CAD/CAM denture system (VITA Zahnfabrik, Bad Säckingen, Germany). ${ }^{29}$ The manufacturing of CAD/ CAM dentures, especially when using preformed denture teeth, requires virtual tooth arrangement procedures with CAD software, and then the data are exported to a CAM system (milling machine or $3 \mathrm{D}$ printers). ${ }^{9,11,20}$ The essential part of this type of CAD/CAM denture process is obtaining correct information about the preformed teeth, so it is important to select a proper tooth brand, which is supported by the program.

For the VITA MFT ${ }^{\circledR}$ groups, the effects of air abrasion were evaluated. After abrasion, the surface of VITA MFT ${ }^{\circledR}$ denture tooth was noticeably smoother than that before the air abrasion. However, the difference in $\mathrm{Ra}$ value was not significant. Bahrani and $\mathrm{Khaledi}^{40}$ reported that the airborne particle abrasion of a ground denture tooth surface demonstrated a significantly improved shear bond strength compared to untreated ones. In our study, however, air abrasion did not improve shear bond strengths.

Most failures of our study occurred at the interface (interfacial and adhesive failure) with some incidences of cohesive failure. Cohesive failure was observed mainly in the Endura Posterio ${ }^{\circledR}$ groups, particularly with conventional heat polymerizing denture resin, and interfacial failure at the denture resin surface also occurred more frequently with the Endura Posterio ${ }^{\circledR}$ groups. This unique pattern might be caused by the lower filler contents and surface hardness of Endura Posterio ${ }^{\circledR}$ teeth. ${ }^{23,24}$ Thean et al..$^{31}$ and Korkmaz et $a l^{39}$ explained that cohesive failure might happen when the 
bond strength of the interface exceeds the strength of the subject material, indicating the formation of stable bonding. Therefore, it does not necessarily indicate that Endura Posterio $^{\circledR}$ teeth have lower shear bond strength than the others. Among them, VITA MFT ${ }^{\circledR}$ groups mostly showed interfacial failures and demonstrated even bond strength to denture base resins regardless of whether they were heatpolymerized or pre-polymerized.

There are some limitations to this study that should be mentioned. Although the shear bond strength is a reliable measure to evaluate the bond strength between materials, ${ }^{31}$ there are many factors affecting the durability of the bonding. A decrease in bond strength after thermocycling has been reported, ${ }^{38}$ and there are many other factors (e.g., $\mathrm{pH}$ changes, water saturation, direction of loading, fatigue from repeated dynamic loading) that may influence the quality of the bonding. Therefore, careful interpretation is needed when applying these results in clinical situations.

\section{CONCLUSION}

This study was conducted to estimate the bond strength of CAD/CAM denture base resins and resin denture teeth bonded with a resin cement. We concluded that the bonding between pre-polymerized CAD/CAM denture base resins and resin teeth bonded with a resin cement was comparable to that of the conventional methods in terms of shear bond strength. VITA MFT $^{\circledR}$ teeth demonstrated more stable shear bond strength compared to the other groups regardless of the types of denture base resin used. Air abrasion on the VITA MFT ${ }^{\circledR}$ teeth did not improve the shear bond strength between denture base resins and denture teeth.

\section{ORCID}

Sang Yeon Han https://orcid.org/0000-0002-2631-0758

Yun-Hee Moon bttps://orcid.org/0000-0003-3926-5738

Jonghyuk Lee https:// orcid.org/0000-0003-1976-4089

\section{REFERENCES}

1. MacEntee MI, Walton JN. The economics of complete dentures and implant-related services: a framework for analysis and preliminary outcomes. J Prosthet Dent 1998;79:24-30.

2. Murray MD, Darvell BW. The evolution of the complete denture base. Theories of complete denture retention-a review. Part 1. Aust Dent J 1993;38:216-9.

3. Zarb GA, Bolender CL, Eckert SE, Jacob RF, Mericske-Stern R. Prosthodontic treatment for edentulous patients. Mosby. 12th ed. 2005. p. 195-7.

4. Jacob RF. The traditional therapeutic paradigm: complete denture therapy. J Prosthet Dent 1998;79:6-13.

5. Lung CY, Darvell BW. Minimization of the inevitable residual monomer in denture base acrylic. Dent Mater 2005;21:111928.

6. Pereira-Cenci T, Del Bel Cury AA, Crielaard W, Ten Cate JM. Development of Candida-associated denture stomatitis: new insights. J Appl Oral Sci 2008;16:86-94.

7. Steinmassl PA, Klaunzer F, Steinmassl O, Dumfahrt H, Grunert I. Evaluation of currently available CAD/CAM denture systems. Int J Prosthodont 2017;30:116-22.

8. Kippax A, Watson CJ, Basker RM, Pentland JE. How well are complete dentures copied? Br Dent J 1998;185:129-33.

9. Goodacre CJ, Garbacea A, Naylor WP, Daher T, Marchack CB, Lowry J. CAD/CAM fabricated complete dentures: concepts and clinical methods of obtaining required morphological data. J Prosthet Dent 2012;107:34-46.

10. Kattadiyil MT, Goodacre CJ, Baba NZ. CAD/CAM complete dentures: a review of two commercial fabrication systems. J Calif Dent Assoc 2013;41:407-16.

11. Kattadiyil MT, Jekki R, Goodacre CJ, Baba NZ. Comparison of treatment outcomes in digital and conventional complete removable dental prosthesis fabrications in a predoctoral setting. J Prosthet Dent 2015;114:818-25.

12. Bidra AS, Farrell K, Burnham D, Dhingra A, Taylor TD, Kuo CL. Prospective cohort pilot study of 2-visit CAD/CAM monolithic complete dentures and implant-retained overdentures: Clinical and patient-centered outcomes. J Prosthet Dent 2016;115:578-86.

13. Maeda Y, Minoura M, Tsutsumi S, Okada M, Nokubi T. A CAD/CAM system for removable denture. Part I: Fabrication of complete dentures. Int J Prosthodont 1994;7:17-21.

14. Kawahata N, Ono H, Nishi Y, Hamano T, Nagaoka E. Trial of duplication procedure for complete dentures by CAD/ CAM. J Oral Rehabil 1997;24:540-8.

15. Kattadiyil MT, AlHelal A, Goodacre BJ. Clinical complications and quality assessments with computer-engineered complete dentures: A systematic review. J Prosthet Dent 2017; 117:721-8.

16. Steinmassl PA, Wiedemair V, Huck C, Klaunzer F, Steinmassl O, Grunert I, Dumfahrt H. Do CAD/CAM dentures really release less monomer than conventional dentures? Clin Oral Investig 2017;21:1697-705.

17. Kanazawa M, Inokoshi M, Minakuchi S, Ohbayashi N. Trial of a CAD/CAM system for fabricating complete dentures. Dent Mater J 2011;30:93-6.

18. Goodacre BJ, Goodacre CJ, Baba NZ, Kattadiyil MT. Comparison of denture base adaptation between CAD-CAM and conventional fabrication techniques. J Prosthet Dent 2016;116:249-56.

19. Han W, Li Y, Zhang Y, Lv Y, Zhang Y, Hu P, Liu H, Ma Z, Shen Y. Design and fabrication of complete dentures using CAD/CAM technology. Medicine (Baltimore) 2017;96:e5435.

20. Ohkubo C, Shimpo H, Tokue A, Park EJ, Kim TH. Complete denture fabrication using piezography and CAD-CAM: A clinical report. J Prosthet Dent 2018;119:334-8.

21. AlHelal A, AlRumaih HS, Kattadiyil MT, Baba NZ, Goodacre CJ. Comparison of retention between maxillary milled and conventional denture bases: A clinical study. J Prosthet Dent 2017;117:233-8.

22. Chai J, Takahashi Y, Takahashi T, Habu T. Bonding durability of conventional resinous denture teeth and highly crosslinked denture teeth to a pour-type denture base resin. Int J Prosthodont 2000;13:112-6. 
23. Zeng J, Sato Y, Ohkubo C, Hosoi T. In vitro wear resistance of three types of composite resin denture teeth. J Prosthet Dent 2005;94:453-7.

24. Choi YS, Lee JS, Cho IH. Comparative study on wear resistance and hardness of several artificial resin tooth. J Korean Acad Stomatognathic Funct Occlusion 2008;24:2:129-46.

25. Suzuki S, Sakoh M, Shiba A. Adhesive bonding of denture base resins to plastic denture teeth. J Biomed Mater Res 1990; 24:1091-103.

26. Kawara M, Carter JM, Ogle RE, Johnson RR. Bonding of plastic teeth to denture base resins. J Prosthet Dent 1991;66: 566-71.

27. Loyaga-Rendon PG, Takahashi H, Hayakawa I, Iwasaki N. Compositional characteristics and hardness of acrylic and composite resin artificial teeth. J Prosthet Dent 2007;98:1419.

28. Lee YI, Cho IH, Lee JS. The effect of various foods on the color stability of artificial teeth. J Korean Acad Prosthodont 2009;47:82-90.

29. https://www.vita-zahnfabrik.com/en/Technician-Solutions/ Removable-prosthetics/Standard-prosthetics/VITA-MFTPosterior-51995,27568.html

30. http://www.shofu.com.sg/downloads/pdf/Endura $\% 20$ Brochure-ref.pdf

31. Thean HP, Chew CL, Goh KI. Shear bond strength of denture teeth to base: a comparative study. Quintessence Int 1996;27:425-8.

32. Patil SB, Naveen BH, Patil NP. Bonding acrylic teeth to acrylic resin denture bases: a review. Gerodontology 2006;23:1319.

33. Pero AC, Scavassin PM, Perin Leite AR, Mendoza Marin DO, Paleari AG, Compagnoni MA. Effect of immersion cleansers on the bond strength between a denture base resin and acrylic resin teeth. Int J Adhesion Adhesives 2013; 44:180-3.

34. Vallittu PK1, Ruyter IE, Nat R. The swelling phenomenon of acrylic resin polymer teeth at the interface with denture base polymers. J Prosthet Dent 1997;78:194-9.

35. Civjan S, Huget EF, de Simon LB. Modifications of the fluid resin technique. J Am Dent Assoc 1972;85:109-12.

36. Takahashi Y, Chai J, Takahashi T, Habu T. Bond strength of denture teeth to denture base resins. Int J Prosthodont 2000; 13:59-65.

37. Kim IJ, Lee JH, Cho IH. A study on the shear bond strength of resin artificial tooth depending on repair techniques. J Dent Rehabil Appl Sci 2005;21:143-51.

38. Saavedra G, Valandro LF, Leite FP, Amaral R, Ozcan M, Bottino MA, Kimpara ET. Bond strength of acrylic teeth to denture base resin after various surface conditioning methods before and after thermocycling. Int J Prosthodont 2007;20: 199-201.

39. Korkmaz T, Dogan A, Dogan OM, Demir H. The bond strength of a highly cross-linked denture tooth to denture base polymers: a comparative study. J Adhes Dent 2011;13: 85-92.

40. Bahrani F, Khaledi AA. Effect of surface treatments on shear bond strength of denture teeth to denture base resins. Dent Res J (Isfahan) 2014;11:114-8.
41. Darbar UR, Huggett R, Harrison A. Denture fracture-a survey. Br Dent J 1994;176:342-5.

42. Bilhan H, Erdogan O, Ergin S, Celik M, Ates G, Geckili O. Complication rates and patient satisfaction with removable dentures. J Adv Prosthodont 2012;4:109-15. 